\title{
Causal Attributions of Test Performance in Accounting
}

\author{
Bettina Greimel-Fuhrmann \\ Vienna University of Economics and Business, Austria
}

\begin{abstract}
Students usually find various explanations for their (good or poor) performance that is reflected in their exam results. These may be internal attributions like their effort and their talent as well as external attributions like their perception of instructional quality, the difficulty of the task and mere (good or bad) luck. This paper analyses empirical data on students' attributions of their learning achievement in accounting. The results show that students attribute both good and bad exam results mainly to their own efforts. Other possible attributions seem to be less important, except for students who have already had negative test results in accounting. These students also attribute bad exam results to their lack of talent for accounting. As talent cannot be influenced easily and students are of course well aware of this fact, motivating these students will always be a challenging task for teachers. This paper discusses different methods that teachers could apply in class in order to motivate these students and to convince them that they can succeed.
\end{abstract}

\section{Problem Statement and Objectives}

People find various explanations for what happens in their lives as well as for their own and other people's behaviour. These explanations are also called attributions or causal attributions. If people do not see themselves as the cause of what is to be explained but use an external cause as an explanation, this kind of reasoning is called external attribution. If they find the explanation in their own person, this process is called internal attribution. People usually tend to attribute success internally and failures externally [e.g. 1, 2].

Attributions are always made, it is an everyday activity and it is well known that attributions influences the way people think and feel about a person or a situation, no matter if the attribution is based and supported by objective facts and therefore correct or is completely inplausible [3].

When it comes to explaining learning achievement and (good or bad) test results, there are also a number of different internal and external attributions possible. Internal attributions refer to the student's effort while studying for the test and his talent. External attributions comprise the good or back luck, the difficulty of the task [4] and instructional quality [5].

It is important to know which attributions students actually use in order to explain their learning achievement. If they attribute good achievement internally to their talent or to the effort they took while studying and their poor achievement is attributed externally to bad luck or the difficulty of the task, they are very likely to perceive their success as positive reinforcement to work hard and take an effort again next time they have to study for an exam. In the case of failure they will be disappointed but still motivated to try harder the next time. All in all, they expect to be successful when they study [6].

However, there are also students who might think that their success is caused by external factors (the exam was easy, they were lucky) and failures are due to their lack of talent. These students are not motivated by success because they do not expect it to last and always expect the next failure [6].

Therefore, learning more about the students' attributions of their good or poor exam results may contribute to understanding how exam results influence motivation, self-efficacy and the willingness to work hard.

Based on empirical data that was collected by surveying students at Austrian commercial colleges this paper examines the students' attributions of good and poor exam results in accounting which is one of the most important subjects that they have to take in this type of school. This paper aims at answering the following questions:

- What kind of explanations do students at Austrian commercial colleges find for their good and poor exam results in the subject accounting?

- Do they attribute good exam results internally and bad ones externally? Which attributions do they make?

- Is there a difference in attributions according to the grades that students actually achieve in the subject accounting? 


\section{The Concept of Attribution}

The expression attribution was coined by Fritz Heider [1] who noticed that people - like "naive scientists" - try to find explanations for what is happening around them in order to understand and maybe even control their environment and their surroundings [7, 8]. The term attribution means the way people explain events in their lives, their own behaviour as well the behaviour of others.

It is an everyday activity and though these explanations may be naive and not based on actual facts they may influence their self-evaluation and their evaluation of other people [3] and have an impact on their emotions and their reactions. According to Weiner's model of achievement attributions an individual's causal attributions of achievement behaviors affect subsequent achievement behaviors and motivation, future achievement expectancies as well as their persistence at similar tasks [9]. Motivation and self-efficacy have proved to be important in learning processes. It is therefore beneficial from a pedagogical point of view to have an insight into students' causal attributions of their learning achievement.

Usually people tend to attribute their success internally. They see the reason and the cause of their success in themselves which helps them to develop and sustain self-esteem [1, 2]. Students could attribute their learning achievement to their effort, their hard work while studying for an exam, their talents and their own abilities and competences. They would probably attribute their success less to instructional quality, to good luck or to the fact that the exam was easy. Failures are often attributed externally so that people do not have to feel miserable about themselves and do not lose their self-esteem. Consequently, students could blame their teachers and their poor teaching performance in class for their failure or attribute their poor exam results to bad luck or the difficulty of the exam.

\section{Design of the Empirical Study}

The data that has been analyzed for this paper was collected for an empirical research project on the evaluation of accounting teachers [5]. The study is based on a questionnaire that was administered to 2,121 students at 24 commercial colleges all over Austria. In order to measure students' attributions of their learning achievement in accounting items were developed that covered different internal (effort, talent) and external (luck, difficulty, instructional quality) attributions. A pretest had shown before that these items actually measure different kinds of attributions as they were highly correlated to other measures of various internal and external attributions.
First students were asked to explain a good exam result in accounting by indicating to which extent each of the following explanations were true:

Let's assume you achieve a very good grade at a written exam on accounting. To which extent are the following explanations true form your point of view?

- I was very well prepared for the exam.

- The exam was easy.

- $\quad$ The teacher has taught me very well.

- I was lucky.

- I have a talent for accounting.

Let's assume that at another test, you have a very poor test result. To which extent are the following explanations true form your point of view?

- It was a difficult test.

- $\quad$ That must be due to bad luck.

- $\quad$ The teacher did not teach me well enough.

- I did not study hard enough.

- I do not have a talent for accounting.

A five point Likert scale was given to indicate the extent of agreement to these statements [10, 11], ranging from „I totally agree (100\%) to „I totally disagree $(0 \%)$. The value 1 was given to the strongest agreement whereas the value 5 indicates the strongest disagreement.

About half of the respondents attended the second year of commercial college and were aged 15 or 16 years. The rest of the students was a few years older, attending the fourth year of commercial college. The mother tongue of $87 \%$ of the respondents is German.

\section{Selected Results}

Table 1 reveals that students attribute good exam results mainly to their effort to study accounting and prepare for the exam. All the other explanations are less important: easy exams and good instructional quality are relevant explanations as well, but the level of agreement to these items is considerably lower. Most interestingly, the least important causal attributions are talent and luck. This result is promising and encouraging from a pedagogical point of view. If students think that their success is mainly caused by their effort, it seems plausible to assume that they can be motivated to study and work hard for the exams.

A lack of effort is also the most important explanation that students have for a poor exam result. Means that exceed the value 3.00 and stand for the students' (strong) disagreement can be found with the attribution of learning achievement to poor instructional quality, a lack of talent and bad luck. Again, this is encouraging because it implies that 
students can be motivated to work harder after achieving bad test results.

Table 1. Causal attributions of good (success) and bad (failure) exam results in accounting (1 indicating strong agreement to 5 indicating strong disagreement).

\begin{tabular}{|c|c|c|c|}
\hline Items & Median & Mean & Std.dev. \\
\hline $\begin{array}{c}\text { Success: } \\
\text { effort }\end{array}$ & 2.00 & 1.9524 & .9576 \\
\hline $\begin{array}{c}\text { Failure: } \\
\text { lack of effort }\end{array}$ & 2.00 & 2.0910 & 1.0179 \\
\hline $\begin{array}{c}\text { Success: } \\
\text { exam was easy }\end{array}$ & 3.00 & 2.7199 & 1.1426 \\
\hline $\begin{array}{c}\text { Failure: } \\
\text { exam } \\
\text { difficult }\end{array}$ & 2.00 & 2.2893 & .9486 \\
\hline $\begin{array}{c}\text { Success: } \\
\text { good } \\
\text { instructional } \\
\text { quality }\end{array}$ & 3.00 & 2.8533 & 1.1523 \\
\hline $\begin{array}{c}\text { Failure: } \\
\text { poor } \\
\text { instructional } \\
\text { quality }\end{array}$ & 3.00 & 3.0580 & 1.1286 \\
\hline $\begin{array}{c}\text { Success: } \\
\text { good luck }\end{array}$ & 3.00 & 3.2482 & 1.2587 \\
\hline $\begin{array}{c}\text { Failure: bad } \\
\text { luck }\end{array}$ & 4.00 & 3.5578 & 1.0779 \\
\hline $\begin{array}{c}\text { Success: } \\
\text { talent }\end{array}$ & 3.00 & 3.4337 & 1.1605 \\
\hline $\begin{array}{c}\text { Failure: } \\
\text { lack of talent }\end{array}$ & 3.00 & 3.2343 & \\
\hline \begin{tabular}{c} 
Valid \\
\hline
\end{tabular} & & & \\
\hline
\end{tabular}

The results presented in table 1 are based on the analysis of all data. It is possible that some respondents have different patterns of causal attribution than the average student. The following analysis is intended to examine the differences between students who have achieved good grades in accounting and those who have had bad grades.

Figures 1 and 2 depict that there are actually differences in the attribution patterns according to the grades that students have achieved in accounting: As has already been shown, the attribution of success to effort is the strongest attribution for both groups of students. However, students who have earned a "very good" or a "good" grade in accounting attribute their success much more to instructional quality and their teacher and less to good luck than students who have earned "satisfactory" or "unsatisfactory" grades. There are also differences as far as the items "success because of effort" and "success because the exam was easy" are concerned, but they are comparatively smaller.

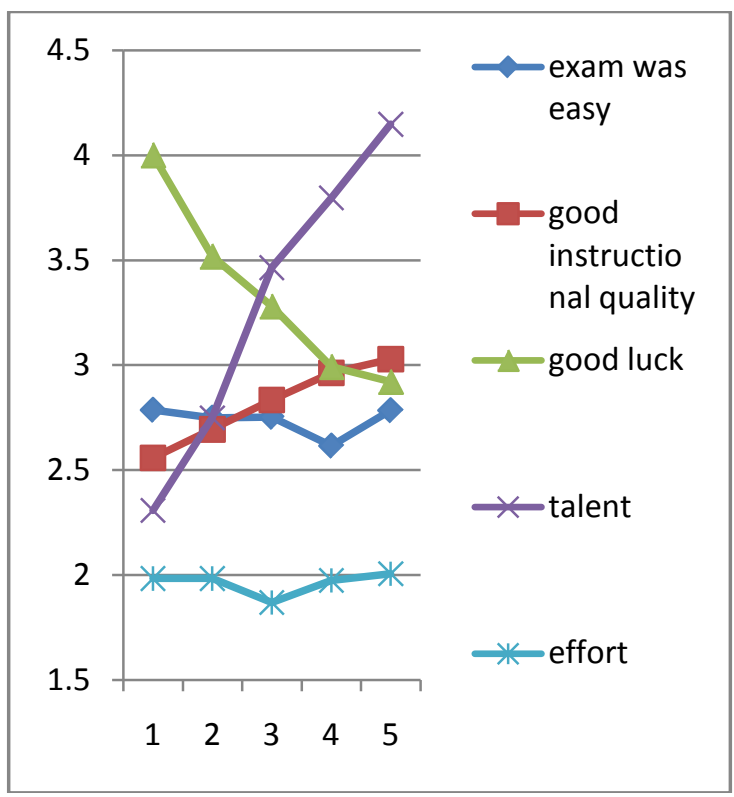

Figure 1. Attribution of good exam results, differences according to grades in accounting, x-axis: grades "very good" (1) to "unsatisfactory" (5)

Students with bad grades attribute bad exam results in accounting mainly to their lack of talent and the difficulty of the task as well as - to a lesser extent - to bad luck and bad instructional quality. A lack of talent is a very important explanation for failure for students with bad grades while it is not for those who have good grades. This kind of attribution is almost irrelevant for them. It is very important for teachers to know about this difference because it has implications for their efforts to motivate students. 


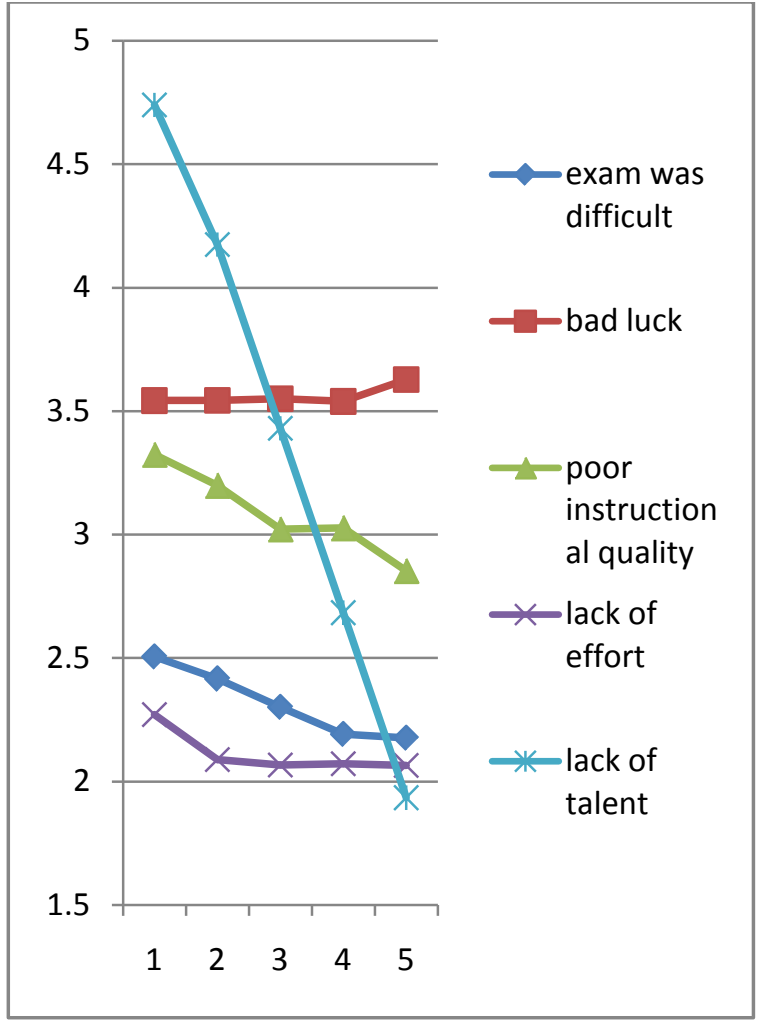

Figure 2. Attribution of bad exam results, differences according to grades in accounting

\section{Summary and Discussion}

The main result of this research project consists in the empirical fact that the dominant causal attribution of students of their good and bad exam results in accounting is the effort (or lack of effort) that students haven taken to prepare for an exam. This internal attribution is favorable for motivating students to work hard to achieve good exam results. All other possible attributions are less important, especially the attribution of success to good luck and the attribution of failure to bad luck. Bad exam results are mainly attributed to the lack of effort and to the difficulty of the task. Instructional quality is used less as an explanation, no matter if success or failure are to be explained from the students' point of view. The main difference between students who achieve good grades in accounting and those who do not consists of the fact that students who achieve bad grades in accounting (who are so-called "underachievers") also attribute their failure strongly to their lack of talent. Talent is a stable factor that cannot be changed easily (or even not at all) and students are of course well aware of this fact and discouraged to study harder. Therefore it seems difficult to motivate these students to work harder because they do not see any sense in taking an effort and study. Leaving them alone during classes is also not conducive to improving their learning achievement because they could possibly interpret this as a confirmation of their belief that they are „hopeless cases“. Anyway, a teacher risks to lose these students and to fail to achieve his or her teaching objectives with these students.

It seems to be indispensable to engage these students in activities in class, to make them solve problems and involve them actively in the problem solving process. They need to experience some success in solving problems in order to experience that they are actually capable of achieving the learning objectives. It is important to convince these students that they can learn from their mistakes and that mistakes are a vital part of learning. By analyzing these mistakes teachers can give diagnostic feedback to the students and help them correct their solutions and understand the learning content. Clarity of explanations, the willingness to explain the learning content by using various examples and to help students when they have problems to understand what they are supposed to learn have proved to significantly influence students' interest in the subject and their motivation to study [5].

\section{References}

[1] F. Heider, The psychology of interpersonal relations, Wiley, New York, 1958.

[2] B. Weiner, Motivationspsychologie. Beltz, Weinheim, 1994.

[3] U.P. Kanning, Die Psychologie der Personenbeurteilung, Hogrefe, 1999.

[4] M. Keßler, Fragebogen zur Kausalattribuierung in Leistungssituationen. Beltz, 1988.

[5] B. Greimel-Fuhrmann, Evaluation von Lehrerinnen und Lehrern. Einflussgrößen auf das Gesamturteil von Lernenden. Studienverlag, Innsbruck, 2003.

[6] H. Zeinz, and A. Scheunpflug, "Selbstbewusstsein und Lernerfolg“. Pädagogik, 10/2010, pp. 36-39.

[7] B. Weiner, An attributional theory of motivation and emotion. Springer, 1986.

[8] J.B. Rotter, "Generalized expectancies for internal versus external locus of control of reinforcement", Psychological monographs, 80, 1966, pp. 1-28.

[9] B. Weiner, S. Graham, P. Stern, and M. E. Lawson, Using affective cues to infer causal thoughts. Developmental Psychology, 18, 1982, pp. 278-286.

[10] J. Bortz, and N. Döring, Forschungsmethoden und Evaluation. Springer, 1995.

[11] H.D. Mummendey, Die Fragebogen - Methode. Hogrefe Verlag für Psychologie, Göttingen u.a., 1995. 